\title{
THE WEB OF POWER RELATIONS AND THE SCHOOL REGULATIVE DISCOURSE DURING PROSPECTIVE TEACHERS' TEACHING PRACTICES
}

\author{
Anna Asimaki ${ }^{1 i}$, \\ Vasiliki-Eleni Selechopoulou', \\ Gerasimos Koustourakis ${ }^{3}$ \\ ${ }^{1}$ Department of Education and Social Work, \\ University of Patras, \\ Greece \\ ${ }^{2}$ School of Education, \\ University of Nottingham, \\ United Kingdom \\ ${ }^{3}$ Department of Educational Sciences and \\ Early Childhood Education, \\ University of Patras, \\ Greece
}

\begin{abstract}
:
The purpose of this paper, which utilises Foucault's theoretical framework, is to study the effect the existent web of power relations and the school regulative discourse have on the formation of the students as teacher-subjects, during their teaching practice organised by a Department of Primary Education in Greece. The data were collected using two research tools: the interview and observation. The research findings showed that power relations are formed between the mentors and the students. Moreover, the mentors' action unfolds on three levels. They simultaneously act as supervisors and evaluators, as lead-teachers in the classroom and as role-models for the students. It is through their action that the students become familiarized the school regulative discourse. The majority of the students conform to the norms of the school regulative discourse and obey the controls exercised by the mentors, during their practicum.
\end{abstract}

Keywords: teacher education; teaching practice; power; regulative discourse; knowledge

\section{Introduction}

School is a disciplinary institution, which aims at the "school normalisation of childhood" (Foucault, 1989; Solomon, 1992, p.321). Within this institution, the educator is simultaneously a transmitter of knowledge and the means for keeping the pupils'

i Correspondence: email asimaki@upatras.gr 
conduct in check. Therefore, he has a direct impact on the final educational outcome (Foucault, 1989; Karras, 2011; Koustourakis, 2007, 2018; Solomon, 1992). The fact that teachers play a central role in the educational process raises a number of questions regarding the content of their training, which are linked to the knowledge and skills they have to acquire.

Teaching practice, as a basic part of future teachers' training, is critical to their formation as teachers. It is the first time they enter the school institution as specially trained educational personnel (Foucault, 2008; Mialaret, 2012).

The research in the international scientific field indicates that the final outcome of teaching practice is directly linked to the way mentors act (Beck \& Kosnik, 2002; Izadinia, 2016; Oikonomidis, 2007). Mentors are responsible for the students' smooth introduction into the school mechanism and the channel, through which they become familiar with the rules and the acceptable forms of action within the school institution (Rajuan, Beijaard, \& Verloop, 2007). As evaluators, they always exercise power over the students, although differences are recorded in its degree of visibility (Koustourakis, 2018; McNay, 2004; Wexler, 2020). However, although mentors can exercise power on students-future teachers (SFT), the latter remain active partners in the developing power relation and hence, can determine their course of action.

The research findings regarding the relation formed between students and mentors, as well as students' stance towards the school norms, seem to coincide in a number of countries, namely Cyprus, Hong-Kong, Canada, Australia and the United States (Beck \& Kosnik, 2002; Hildenbrand \& Arndt, 2016; Izadinia, 2016; Loizou, 2011; Santoro, 1999). However, the review of the Greek and international scientific literature indicates a lack of recent studies that focus on the practicum of SFTs in the field of primary education.

The purpose of the current study is to examine the effect power relations and the school regulative discourse have on the action and the body of SFTs during their teaching practice at a Department of Primary Education in Greece.

This paper begins with an approach to the concepts from Michel Foucault's theoretical framework that are utilized in this research, and this is followed by the section containing the research questions and methodology. Then the research findings are presented and analyzed and the section containing the discussion and conclusions completes the paper.

\section{Theoretical framework}

This study utilises the concepts of power, discipline, disciplinary power and regulative discourse, as defined in the theoretical framework of M. Foucault. This theory provides us with the opportunity to focus on individual institutions and techniques, like the school and the practicum (Foucault, 2008, 2016a; Asimaki, Koustourakis, \& Nikolakakos, 2000). In Foucault's theory, the concept of power doesn't align with traditional definitions and differs from the concept of sovereignty (Foucault, 2005, 2008, 2016a; Lazaroiu, 2013). It is 
presented as inherent in the meeting point of two or more individuals and is based on the inequality of force among them. Therefore, power is ubiquitous and cannot be possessed. It is defined as an "action on the actions" of others and each individual can simultaneously be its transmitter or the base of its articulation (Deleuze, 2005; Foucault, 1991, pp. 91 and 107; Foucault, 2010; Jones \& Ball, 1994).

The main precondition for the existence of power relations is the recognition of individual freedom. Freedom is defined as the subject's active consent to participate in the game of power. It grants the subject the ability to move within its field of possibilities, as it is formed by the dominant discourses and the existent web of power relations (Foucault, 1991, 2005; Pitsoe \& Letseka, 2013; Veyne, 2011). However, a practice of freedom, essential for the formation of power relations is resistance. It can be conceived as an action aiming at the inversion of the power relations in effect (Buckland, 2016; Foucault, 1989, 1991, 2008, 2016a; Lilha \& Vinthagen, 2014). From this point of view, the SFTs, during their practicum, are free to either conform to the external controls and rules or to resist them.

A special form of power, which is dominant within the school institution, is disciplinary power. Its aim is to produce docile and useful subjects -in this case, SFTsthat have internalised the school norms (Foucault, 1989, 1991, 2010). This form of power proceeds to a detailed analysis of the subjects, aiming to normalise their action (Foucault, 2008). In order to achieve this aim three mechanisms are activated: hierarchical observation, normalizing judgment and examination (Foucault, 1989, pp. 228-254).

The effectiveness of disciplinary power within the school institution is linked directly to a plurality of methods and mechanisms that focus on detail and in Foucault's theory constitute discipline. Via the mechanism of discipline, individualized supervision of the subjects can be achieved. Therefore, a system based on the maximum use of time, the enclosure of space and the imposition of repetitive tasks by specialised personnel is structured. So, discipline is a technology of power that forms trained and dutiful bodies that act in accordance with the dominant norms (Foucault, 1989, pp. 184 and 198-206).

Norms are the regulative principles that define the acceptable ways in which the subject may act within each institution (Foucault, 2010; Troulinou, 1991). In school, norms are defined by the school regulative discourse - a web of statements that delineate truth (Armstrong, 2015; Foucault, 1990, 2005). The constitution of the regulative discourse is directly related to the characteristics of each field, in this case, the educational field, and is articulated through a body of knowledge (Armstrong, 2015; Foucault, 1990). Within each institution, power relations and the dominant discourse determine the basic characteristics that subjects should possess (SFTs) (Buckland, 2016; Foucault, 1990).

Based on Foucault's theoretical framework, we speculate that during the SFTs practicum the school regulative discourse will prevail. This will impact on the action and the body of the students at the micro-level of the school classroom. Furthermore, the exercise of disciplinary power is anticipated, which aims at the internalisation of the school norms by the SFTs, so that they can successfully staff the disciplinary institution of the school afterwards. 


\section{Research questions - Methodology}

In this paper we tried to explore and answer the following research questions:

1) What effect does the mentors' action have on the action and the body of the SFTs, within the web of power that is constituted during the practicum?

2) Does the school regulative discourse impact on the formation of the SFTs as teaching subjects?

In the present study, we applied triangulation, gathering the data through the use of two research tools, structured observation and the semi-structured interview (Mason, 2002; Silverman \& Marvasti, 2008).

Structured observations were selected as a research tool, as they allow us to focus on the actions of SFTs and their mentors during their teaching practice (TP). The observation guide was constructed based on the purpose of the study, the theoretical framework and the data from an unstructured observation which preceded, in order to identify the special characteristics of the field. The effectiveness of the guide was pilottested.

The research tool of semi-structured interviews was selected in order to achieve an in-depth discussion with the study's research subjects. The interview protocol was designed with regard to the purpose of the study, its theoretical background and the findings of the observations that had already taken place. It was pilot-tested to ensure that any deficiency was corrected (Mason, 2002).

The study sample consisted of 16 students (12 female, 4 male) at a Department of Primary Education in a Greek University. They were selected using convenience sampling (Babbie, 2010) and were all in their final year. It should be highlighted that at the examined Department of Primary Education, teaching practice takes place during the 4th year of studies and lasts one semester. Each student teaches for 13 days and follows the teaching timetable of the classroom in which they do their TP. Moreover, for a total of 25 days, SFTs observe their supervising mentor's teaching. The mentor is the corresponding class teacher. For this role, the mentor is trained through a mandatory training programme, which is organised by the Department of Primary Education in question. Each mentor supervises two students.

Data collection began in May 2017 and lasted three months. Each participant was observed twice. The interviews were individual and were carried out in a setting of the research subjects' choice to ensure a feeling of familiarity (Vamvoukas, 2000). In the course of the data collection, we took ethical issues into consideration. The participating SFTs were thoroughly informed about the purpose of the study and consented to participate. Additionally, the researchers ensured the anonymity of the research subjects (Babbie, 2010).

The collected data were analysed through the technique of qualitative content analysis. The theme was selected as a unit of analysis. We focused on the manifest content of the research data, aiming to ensure the reliability of the study (Krippendorff, 2004; Kyriazi, 2000; White \& Marsh, 2006). The reason why qualitative analysis of the 
observation and interview data was applied, was to ensure a deep and multilevel analysis of the examined phenomenon, which allows us to illustrate subjects' thoughts and actions (Grawitz, 2006).

Based on the purpose and the theoretical framework of the study, the 'appropriate' analysis categories were established. Specifically, regarding the research tool of observation, we designed the following 2 categories and 1 subcategory:

1. Mentors' control of students' action

1.1 The presence and the position of mentors within the field of the classroom

2. The impact of the school regulative discourse on students

As regards our second research tool, the interview, we formed 3 categories and 3 subcategories:

1. Mentors acting as supervisors- evaluators of students

1.1 Mentor's action during students' TP based on his/her position in the school institution

2. The mentor as a bearer of the school regulative discourse during the TP

2.1. Students' action: conformity and internalization of mentors' control

3. Cases of students' resistance

3.1. Effect of school regulative discourse on students' action and body: the formation of docile subjects

\section{Results}

\subsection{Findings of the observations}

\subsubsection{Mentors' control of students' action}

Mentors as supervisors are able to exercise power over SFTs' action (Foucault, 1991). This can be verified by the data gathered through observation. Furthermore, mentors seem to exercise verbal and less frequently, non-verbal controls during SFTs' teaching, which directly or indirectly determined the students' action. The aforementioned controls can be divided into two groups. The first includes interference aimed at the modification of the SFTs' action (orders, advice, and comments on how to speak and move in the classroom). The second group is separated into two cases. The first refers to SFTs' course of instruction (advice on knowledge content and teaching methods) and the second to the behaviour of the children in the classroom and was aimed at maintaining discipline. In order to illustrate the degree of control exercised directly over students' action, we designed Table 1, in which three gradations of control over the SFTs action were identified, based on the processing of the collected observation data. More specifically, mentors exercise weak $\left(\mathrm{C}^{-}\right)$, medium $\left(\mathrm{C}^{+}\right)$, or strong $\left(\mathrm{C}^{++}\right)$control over SFTs' action. Mentors who exercise weak control, interfere to a small extent with students' teaching and choose indirect controls, like advice and comments. In contrast, those who exercise medium control tend to interfere more often in the SFTs' teaching, whereas mentors that exercise strong control, determine the students' teaching to the greatest degree possible, by intervening directly and imposing sanctions (Foucault 1989, 1991). 
Table 1: Degree of mentors' control over supervised SFTs' action

\begin{tabular}{l|l}
\hline $\mathrm{C}^{-}$ & M02, M04, M05, M07, M08, M12, M14, M15, M16 \\
\hline $\mathrm{C}^{+}$ & M03, M06, M09, M13 \\
\hline $\mathrm{C}^{++}$ & M01, M10, M11 \\
\hline
\end{tabular}

The distribution of mentors as indicated in Table 1, shows that the majority of them (C-: 9 mentors, $56.25 \%$ ) exercises weak control over the action of both supervised students, whereas there are fewer cases, in which medium (C+: 4 mentors, $25 \%$ ) or strong control (C++: 3 mentors, $18.75 \%$ ) is exercised.

Concerning the second group, Table 2 illustrates the distribution of mentors that exercise the same degree of control on both of the supervised SFTs, regarding the course of their instruction and pupils' action in the classroom concerning matters of discipline.

Table 2: Degree of mentors' control on the course of students' instruction and on pupils' discipline

\begin{tabular}{l|l}
\hline$C^{-}$ & M06, M03, M04, M13 \\
\hline$C^{+}$ & M01 \\
\hline$C^{++}$ & M08, M10, M11 \\
\hline
\end{tabular}

Focusing on the data in Table 2, it seems that 8 out of the 16 mentors (percentage: $50 \%$ ) exercised the same degree of control on both of the supervised students. Specifically, 4 out of these 8 mentors exercised weak control on both of the students (C-: percentage $25 \%$ of the total number of mentors) and interfered to a small degree with the SFTs' teaching and disciplinary responsibilities. However, the remaining 4 mentors $\left(\mathrm{C}^{+}, \mathrm{C}^{++}\right.$: percentage $25 \%$ of the total number of mentors) didn't give students the leeway to take initiatives during the teaching act and interfered on matters of discipline and pupils' obedience.

Table 3 presents the action of the other 8 mentors, who exercised a different degree of control over the two students each of them supervised. It should be highlighted that the shaded parts of the Table indicate the differentiated exercise of each mentors' control over the students, concerning the course of their instruction and pupils' discipline.

Table 3: Mentors' control differential between the two supervised SFTs

\begin{tabular}{l|l|l|l}
\hline \multicolumn{3}{|c|}{ C } & \multicolumn{1}{c}{$\mathrm{C}^{+}$} \\
\hline M07 & & & \\
\hline M09 & & & \\
\hline M12 & & & \\
\hline M14 & & & \\
\hline M15 & & & \\
\hline M05 & & & \\
\hline M02 & & & \\
\hline M16 & & & \\
\hline
\end{tabular}

Examining the data in Table 3, we conclude that the mentors' action is directly linked to the body of knowledge they collect for each of the supervised students by observing their 
action. Therefore, mentors, being aware of the characteristics and divergences of each SFT, can adjust the degree of control they exercise correspondingly (Foucault, 1989, 2010).

\subsubsection{The presence and the position of mentors within the field of the classroom}

The position selected by each mentor within the classroom affects students' action (Deleuze 2005). Table 4 illustrates the positions occupied by mentors within the classroom during SFTs' instruction. According to the observation data, mentors chose either to be seated at the teacher's desk (TD), or to stand near the whiteboard (WB), in order to intervene in students' instruction, or to stand between students' desks (SSD), or to remain seated with the students, at one of their desks (SS), or to remain at the side and at the back of the classroom (S/B). Moreover, it was noticed that in some cases mentors were absent $(\mathrm{A})$ from the classroom for an extended period of time.

In order to depict the length of time mentors occupied positions within the classroom, we used three graduations: three circles $(\bullet \bullet \bullet)$ correspond to the mentor remaining in a specific position for a long time, two circles $(\bullet \bullet)$ to a medium duration, and one circle $(\bullet)$ to a minimum amount of time spent in a position. The dash (-) indicates the absence of data for a specific position.

Table 4: Mentors' positions in the classroom during students' instruction

\begin{tabular}{|c|c|c|c|c|c|c|}
\hline & TD & WB & SSD & SS & S/B & A \\
\hline M01 & $\bullet \bullet$ & - & $\bullet \bullet$ & $\bullet$ & $\bullet \bullet$ & - \\
\hline M02 & 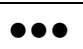 & - & $\bullet$ & - & • & - \\
\hline M03 & $\bullet \bullet$ & $\bullet \bullet$ & $\bullet$ & - & $\bullet \bullet$ & $\bullet \bullet$ \\
\hline M04 & $\bullet \bullet$ & - & - & - & $\bullet \bullet$ & $\bullet \bullet \bullet$ \\
\hline M05 & $\bullet$ & - & - & $\bullet \bullet \bullet$ & • & - \\
\hline M06 & $\bullet \bullet \bullet$ & - & •• & - & • & • \\
\hline M07 & - & •• & • & - & $\bullet \bullet$ & • \\
\hline M08 & $\bullet \bullet \bullet$ & $\bullet \bullet$ & - & - & - & - \\
\hline M09 & $\bullet \bullet \bullet$ & $\bullet$ & $\bullet$ & - & - & - \\
\hline M10 & $\bullet \bullet \bullet$ & - & $\bullet$ & - & - & - \\
\hline M11 & 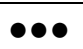 & •• & •• & - & • & - \\
\hline M12 & - & - & $\bullet$ & - & $\bullet \bullet \bullet$ & - \\
\hline M13 & - & - & - & - & $\bullet \bullet \bullet$ & - \\
\hline M14 & $\bullet \bullet \bullet$ & - & - & - & - & - \\
\hline M15 & $\bullet \bullet \bullet$ & - & - & - & - & - \\
\hline M16 & 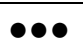 & - & - & - & - & - \\
\hline
\end{tabular}

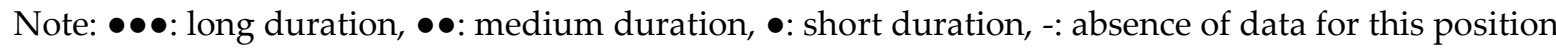

Table 4 shows that mentors tend to remain in the classroom during most of the students' instruction, in order to supervise them. Focusing on the positions in which mentors spend

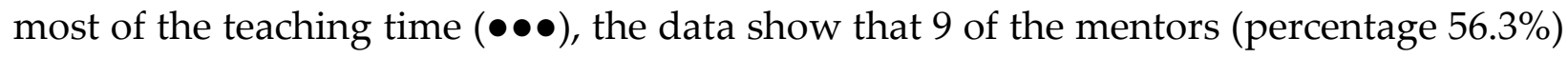
were seated at the teacher's desk, which can be characterised as a symbol of the educator's power. This choice indicates that mentors refuse to concede their position as lead teachers to the trainees. Moreover, only 2 mentors chose to stand at the side or at the back of the classroom for a long time, where they exercise the minimum impact on students' 
instruction. However, if we add to this finding the mentors that spent a medium amount

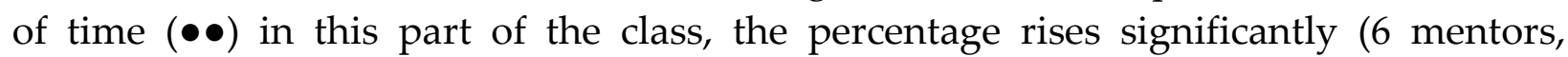
percentage $37.5 \%$ ). The remaining two positions are related to the placement of mentors' 'bodies' in the classroom: a) near the whiteboard (9 mentors, percentage $56.3 \%$ : 4 long and 5 medium time period), from where they can intervene and regulate the course of instruction, and b) standing between pupils' desks (12 mentors, percentage 75\%: 3 long, 9 medium duration), making their presence visible. Only 4 of the mentors (percentage 25\%: 1 very frequently, 2 less often) assigned to the students in the sample were absent during their teaching hours.

From this point of view, the mentors' supervision is based on terms of visibility and mechanics (Deleuze 2005; Foucault 1989, 236). So, inside the enclosed classroom space, every spot is controlled and every movement is recorded, following the panopticon archetype. The mentors' surveillance becomes intensive and functional, thus it multiplies the efficiency of their training and achieves students' addiction to normativity (Foucault, 1989, p. 261; Tasi, 2014).

\subsubsection{The impact of the school regulative discourse on students}

The school regulative discourse shapes the norms that define what is acceptable and what is not within the school mechanism and regulate subjects' action (Foucault, 1994, 2010; Troulinou, 1991). The dominant school norms are founded on the principle of productivity, namely the exhaustive use of school time aiming at the maximum efficacy, and define the teaching material and methods, as well as the time limits (Foucault, 1989; Solomon, 1992).

Focusing on each of the aforementioned 'normative imperatives', concerning the teaching material, complying with the norms equals the exclusive transference of the chosen and proper knowledge included in the schoolbooks (Kossivaki, 2003). Regarding the teaching methods applied, SFTs conform when they utilise teacher-centred methods, such as the lecture. On the other hand, they resist if they choose to apply alternative student-oriented teaching methods (Solomon, 1992; Koutselini-Ioannidou, 1996). As regards the time limits, the acceptance of time restrictions concerning arrival, teaching and departure that are set in the school institution is noted as compliance.

Observations of students' action showed that the percentage of compliance regarding the teaching material reached $87.5 \%$ (14 students), whereas the percentage of resistance is only $12.5 \%$ ( 2 students). Moreover, $68.75 \%$ (11 students) of the SFTs complied with the norms concerning the acceptable teaching methods, while $31.25 \%$ (5 students) resisted. Finally, all of the SFTs obeyed and internalised the rules that referred to the set time restrictions.

Therefore, based on the findings from our observation, we can state that a great percentage of students complies with the salient norms. It can be speculated that the recorded compliance is related to the constant supervision and evaluation of the SFTs by the mentors (Foucault, 2010; Veyne, 2011). 


\subsection{Findings from the interviews}

\subsubsection{Mentors acting as supervisors-evaluators of students}

The mentors' role includes supervising and evaluating the SFTs, while they teach in the classroom, during their TP. Thus, they are 'bearers' of power and their action impacts on SFTs' action at every stage of the TP (plan, execution, teacher-subject formation) (Foucault, 1991).

Starting from the planning phase, a differentiation was noted in the degree of communication between the mentors and the SFTs in the sample. However, no case of instruction co-planning was recorded:

"We never designed a teaching plan with the mentors. We had no such contact." (S08)

"We never happened to co-plan a lesson with the mentor." (S10)

The final outcome of the planning phase was the teaching plan, namely a document which the SFTs handed in to the mentors so that they could observe and evaluate their instruction (Foucault 1989). Differences were mentioned regarding the deadline mentors set for the delivery of the teaching plans by the SFTs. Most mentors required that the delivery preceded the instruction, in order for them to be able to successfully supervise it:

"My mentor always asked for the teaching plans to be ready the day before the instruction." (S09)

The teaching plan, as a document, is a means of examination and leads to the conclusion that TP is based on a "power of writing". Through the collection of documents, mentors raise a body of individualised knowledge on each student, which makes each one a special "case" (Foucault 1989, 250-251).

Moving on, during the students' teaching, the mentors' supervision intensified. They observed and often kept notes on the way the SFTs taught:

"Mentors always supervise my instruction. They see how I'm teaching and they keep notes." (S14)

"While I teach, mentors observe the progress of my instruction." (S08)

However, students also referred to cases in which mentors occupied themselves with tasks that were not related to their teaching instruction. One student mentions:

"While I taught, mentors listened to me mechanically. They usually corrected books, notebooks, or made collages." (S09) 
The mentors' supervisory role was complete after the feedback discussion, which usually followed the students' teaching and depended on the use of two disciplinary techniques, rewards and sanctions (Foucault, 2005, 2010). A differentiation was noted in the way mentors approached SFTs during these discussions:

"The teacher made unpleasant comments and she shouldn't (...). She wanted to have control." (S01)

"I can't say that I feel bad when the teacher makes remarks on my teaching, because he makes them nicely. If he tried to put me down, I would get upset." (S06)

From the data collected, it appeared that during TP the mechanism of hierarchical observation was activated. Mentors exercised disciplinary power on the SFTs, aiming to transform them into docile bodies with 'proper' conduct (Foucault 1989, 2005, 2008, 2010). Therefore, the trainees were constantly visible to the eye of the mentors and were subjected to a series of assessments. Their teaching was observed and assessed based on the binary of acceptable and unacceptable, which the school regulative discourse imposes (Foucault, 1989, 1991, 2008, 2010).

\subsubsection{Mentor's action during students' TP based on his/her position in the school institution}

Mentors are students' supervisors, but at the same time, they try to maintain their role as lead teachers in the classroom, through their professional position. Hence, they exercise their power through verbal or non-verbal controls, aiming to secure their privileges (Foucault, 1991, 2008).

The data show that mentors exercised power on SFTs' action in order to guide their conduct and to delimit their possible actions (Foucault, 1991, p.92). They defined their potential for action and set boundaries, aiming to discipline them:

"The teacher sets his own boundaries in the classroom. One cannot exceed or diminish them." (S07)

"During the TP I have learnt from experience that some things are beyond my reach. Once I took the initiative to change two pupils' seats and then I realised that it wasn't acceptable for my mentor, the class teacher." (S05)

Moreover, mentors tended to intervene during the planning and execution of the instruction by the SFTs. Their interference was recorded as an effort to define the content and the course of the students' teaching:

"The mentor told us: 'I want this and that and I don't think you will have time for anything else. (...) We had too much guidance and she wanted to have control." (S01) 
"There were some lesson plans that the mentor thought were effective. So, she told me that it would be better if I followed her guidelines." (S13)

However, there were also cases in which mentors gave SFTs the leeway to plan their teaching as they saw fit:

"My mentor gave me the main teaching frame and from there on I had no constraint. He let me act the way I liked." (S08)

During the students' teaching, the mentors usually intervened in matters of discipline and enhancement of the teaching:

"When the children are noisy, mentors intervene, because due to their position, they can guarantee order." (S05)

"Because the mentor knew exactly what to say for the pupils to understand her, she intervened while I taught, in order to explain." (S16)

It can be noticed that mentors' interventions focused mainly on matters of discipline and knowledge. Therefore, they were related to the main responsibilities of a teacher, namely the transfer of knowledge and the maintenance of order in the classroom (Foucault, 1989; Solomon, 1992).

In some cases, though, as the following extract depicts in a characteristic manner, mentors completely set SFTs aside and taught by themselves:

"I was trying to teach, to speak, but the mentor had taken control. She told the children how to do the experiments and taught the lesson by herself." (S11)

In this case, the mentors' action restricted the students' field of possibilities and freedom in the classroom. Hence, the power relation between mentors and SFTs reached the limits of a sovereignty relation (Asimaki, Nikolakakos, \& Vergidis, 2016; Foucault, 2005, 2008).

Furthermore, many cases were recorded, in which mentors sought to maintain their status through their position in the classroom. They either moved around, or sat at the teacher's desk, or remained standing in order to be visible to the pupils (Foucault, 1989):

"[The teacher] was everywhere in the classroom. Usually, she sat at the teacher's desk, sometimes she moved around and handed out worksheets..." (S15)

To sum up, it is obvious that the students' field of possibilities is formed by the mentors' constraints and controls, as mentors are bearers of power and can impose the 
school norms. Therefore, in such cases, a power relation is formed between mentors and SFTs, in which, due to the differentiation in their force, the former strived to maintain their role as lead teachers in the classroom (Foucault, 1989, 1991, 2008; Solomon, 1992).

\subsubsection{The mentor as a bearer of the school regulative discourse during the students' TP} The teachers constitute a stable body of professional knowledge, due to their long-term interaction with the school regulative discourse, which ensures acceptance and effectiveness within the school institution (Koutselini-Ioannidou, 1996). Therefore, mentors, as experienced and knowledgeable teachers, are often characterised as role models and transmitters of experience:

"[The mentor] shows me how to teach and I try to adapt to what he proposes." (S10)

"The truth is that I watched the mentor from top to toe to see how he teaches. In my opinion, his experience is there to give us what we lack." (S07)

However, only a few cases emerged through the testimonies of the students, in which mentors introduced the SFTs to alternative teaching methods:

"The mentor told me not to rely on the books and prepare my own teaching material (...) he applied a variety of methods that we learnt at the university." (S03)

Therefore, the mentors' action as experienced teachers seems to have a decisive effect on the shaping of the SFTs' teacher-profile during their TP.

\subsubsection{Students' action: conformity and internalization of mentors' control}

Students are one of the two active "partners" in the power relation formed between them and the mentors. According to the collected data, SFTs recognise the control exercised by the mentors and usually even seek it. They describe it as an essential prerequisite for their action. Hence, they become "the principle of their own subjection" (Foucault, 1989, 268). The following extracts are indicative:

"I would rather the mentor stayed in the classroom during all of the instruction so that she could control the situation (...) so that she could correct me." (S09)

"I feel insecure and I often ask the mentor. Maybe I shouldn't interrupt the instruction to do so, but I do..." (S15)

The students' main reaction to the normalising controls exercised by mentors during their teaching is conformity (Foucault, 1989, 1991, 2005). Conformity is recorded concerning matters of planning, the teaching method and content, and classroom 
management. Students state that the teachers' position and experience within the school institution, as well as their role as evaluators, are the main reason they comply:

"I listen [to the mentor], because of the nature of her role." (S05)

"I want to teach properly, especially due to the mentor's assessment. Therefore, it affects the way I teach." (S13)

The majority of the students comply with the teacher ideal suggested by the mentors. The external controls that are exercised are gradually internalised by the students and, hence, transform their action (Foucault, 2008). Thus, through the exercise of supervision and control, these become an integral part of the supervised students and turn them into docile subjects (Aravanis, 1996; Foucault, 1989, 170, 1991, 2005, 2008).

\subsection{Cases of students' resistance}

Specific cases of resistance by a small group of students (5 SFT, percentage 25\%) emerged from our interview data. The students' ability to resist confirms that a power relation is formed between students and mentors, in which the former has the leeway to define their action (Deleuze, 2005; Foucault, 1991, 2008).

By choosing to resist, the SFTs oppose the external coercion (Foucault, 1991, pp. 79-81, 2008; Lilha \& Vinthagen, 2014). SFTs' resistance was mainly recorded regarding the mentors' action and the teaching methods they proposed:

"I did what I regarded as right. In History lessons, the mentor told me how she teaches, but I wanted to use diagrams and so I did." (S06)

"Despite the mentors' supervision, I tried to apply what I wanted. I didn't do exactly what the mentor told me to. I acted differently, in spite of his criticism." (S03)

Consequently, there were SFTs that chose to actively oppose the mentors' guidance. These cases reflect a practice of the students' freedom, which is linked to their voluntary formation as teacher subjects (Butler, 2017; Foucault, 2016b).

\subsubsection{The effect of school regulative discourse on students' action and body: the formation of docile subjects}

The school norms are constituted within the school institution, through the application of the curriculum and gradually form the school regulative discourse (Foucault, 1989, 2010). Norms, as regulative principles, are associated with the body and the action of the teacher, the spatiotemporal frame, the acceptable disciplinary techniques and the transfer of knowledge (Aravanis, 1996; Kossivaki, 2003). The SFTs can decide between complying with and resisting the school norms (Foucault, 1994, 2005, 2010; Lilha \& Vinthagen, 2014). 
Regarding the teachers' action, norms mandate careful behaviour. Moreover, teachers have to maintain distance from their pupils. As for the teachers' body, the school rules command homogenous and conservative dress and appearance (Braun, 2011; Sumara \& Luce-Kapler, 1996). The students' espousal of the dominant norms is depicted in a characteristic manner in the following extract:

"I always choose a more conservative outfit. Overall, I consider that a dress code is necessary at a school." (S08)

"I have some tattoos and I thought that there is no point in children seeing them. I made sure that my clothes covered them." (S07)

From the students in our sample, only one chose to oppose the norms that mandate homogeneity in their appearance:

"I didn't take my nose ring off, because children should accept diversity. That's why I kept it in!" (S11)

Moreover, school norms define the way teachers handle time and space. Regarding time management, the aim is the exhaustive use of school time based on a stable timetable, which teachers must respect (Koutselini-Ioannidou, 1996). As for the management of space, the traditional layout consists of student desks arranged in parallel lines and pupils divided into twos, namely a cellular layout that facilitates supervision (Foucault, 1989, pp. 188,195; Germanos, 1993; Solomon, 1992). During their TP students seem to embrace the norms regarding the proper organization of time and space, in order to secure children's obedience:

"First of all, I try to keep track of time, so that I don't have to take time off the following lesson." (S08)

"The desks' layout depends on how quiet the class is. When the class is arranged in teams, one cannot keep an eye on all the pupils. I think it is better if they are divided into twos." (S04)

Compliance with the school norms is also detected regarding the applied disciplinary techniques. According to Kossivaki (2003), Greek educators tend to apply traditional disciplinary techniques, like repetitive series of tasks and threats, in order to maintain pupils' discipline:

"I have seen teachers that have imposed order. Children know that when the Greek language lesson is over, they have to close their books, put them in their bags. There is a 
routine and everyone respects it. (...) So, I would like it if my class was organised in such a way." (S04)

The teaching method and the transferred knowledge are also controlled through in-school rules. The dominant tendency for Greek teachers is the exclusive use of textbooks and teacher-centred instruction. The teachers' movement in the classroom is confined near the teacher's desk and the whiteboard (Kossivaki, 2003). The majority of the students apply this traditional way of teaching:

"The instruction is mainly based on the textbooks (...). This is what I have learned from my experience with the mentors. It is a well-trodden path and I see that it is effective." (S09)

"I mainly write on the whiteboard and follow the traditional teaching method." (S13)

Based on our findings, we can suggest that the school community functions based on stated or unstated rules aimed at the formation of a specific type of teacher subjects. Observing the students in the sample, it seems that in their effort to be integrated into the school institution, they usually comply with the school norms (Foucault, 1989, 2005, 2010; Jones \& Ball, 1994).

\section{Discussion and conclusions}

The purpose of the present paper was the detection of the effect mentors' action and the school regulative discourse have on the action and the body of student-teachers at a Department of Primary Education in Greece, during their TP.

The findings of our research indicate that the school regulative discourse dominates in the school field, which the SFTs enter during their TP. Its norms define the way the school community is organised. During their TP, students mostly comply with and internalise the rules. The mentor's role is central to this (Foucault, 1989, 2005, 2010; Koutselini-Ioannidou, 1996; Veyne, 2011).

The research results show that mentors and students constantly interacted within the classroom, forming a relation of power and dependence. Specifically, mentors were able to exercise power over the SFTs who taught in their classrooms, due to their role and position in the school institution (Foucault, 1991, 2008).

The mentors' action can be analysed at three different levels. Firstly, mentors acted as supervisors and evaluators of the SFTs during their teaching. At this level, their action was driven by the criteria set by the school regulative discourse, regarding the formation of the teacher subject. At a second level, the mentors' action was oriented towards the maintenance of their position as lead teachers in the classroom (Britzman, 2003). Therefore, some of them interfered intensely with the SFTs' teaching by taking control of it and even teaching by themselves. At a third level, the mentors operated as role models, 
constituting the channel through which SFTs became familiar with the salient normalising practices operating in the school institution (Rajuan, Beijaard, \& Verloop, 2007).

The mentors' main responsibility was the formation of the student-teacher subjects and their guidance towards the espousal of "normal" and acceptable conduct as this is outlined in the dominant school norms (Foucault, 2010). In order to achieve this, mentors exercised disciplinary power on the SFTs, forcing them to internalise the school norms (Foucault, 1991, 2005, 2010). Specifically, four disciplinary mechanisms were activated during the students' $\mathrm{TP}$, in order to successfully transform them into docile teacher subjects: examination, hierarchical observation, communication and normalizing judgment. The examination was based on the diligent observation of the students' teaching and the collection of documents, like the teaching plans, in order to facilitate their assessment (Foucault, 1989, 2008, 2010; Tasi, 2014). Hierarchical observation reinforced the examination mechanism, assisting students' submission (Deleuze, 2005, pp. 103-105; Foucault, 1989). Mentors were the eye of power, which spotted every deviation and 'cured' it (Foucault, 1989, 1991, 2008). Communication between mentors and SFTs was also used as a basic control and treatment mechanism (Abrahams, 2009). The research findings indicate that mentors chose to exercise negative controls and sanctions on SFTs, whereas only a few mentors used positive comments and rewards (positive control). These findings differ from the findings of the research conducted by Edwards and Collison (1995).

Within the relation formed between mentors and students, SFTs reacted to the exercised disciplinary coercion in two ways: a) by conforming, which was recorded more often, or b) by resisting the mentors' suggestions. The former shows the SFTs' internalization of the norms of the school regulative discourse, while the latter indicates the application of alternative teaching methods (Foucault, 1989, 2008, 2010, 2016b).

Moreover, the findings of the present paper show that three types of power relations are formed between mentors and students. The first type is the powerfulpowerless relation, in which the mentor seeks to entirely define the SFTs' field of possibilities. The second type refers to a powerful-empowered relation. In this case, mentors seek to exercise their power invisibly and encourage students to take initiatives (Rajuan, Beijaard, \& Verloop, 2007; Loizou, 2011). The third type of relation, which occurred in fewer cases, is the powerful-resistant relation, in which mentors try to define SFTs' action, but the latter resist and refuse to comply with the norms (Foucault, 1991).

To sum up, TP can be characterised as a technique, which includes tasks both repetitive and different, aiming to transform students into teachers (Foucault, 1989, p. 212). Mentors, as working teachers, become the channel, through which SFTs interact with the demands of the school regulative discourse. Therefore, they have a direct impact on their bodies and action. However, this does not always lead to conformity, as SFTs are active and free subjects, who can oppose the school norms.

The conclusions of the present paper illustrate the need for further research in Greece, as well as abroad, on the contribution of TP, which takes place during future 
teachers' studies at the university. One thing is certain, TP surely affects the professional path of future teachers to either a greater or lesser degree.

\section{Acknowledgements}

This research did not receive any specific grant from funding agencies in the public, commercial, or not-for-profit sectors.

\section{About the Authors}

Anna Asimaki (PhD) is Associate Professor at the University of Patras, Department of Education and Social Work, Greece. She is also a tutor in the postgraduate studies programme in the same Department, teaching professional development for teachers. Among her publications is the article entitled "Regulative discourses of primary schooling in Greece: memories of punishment", International Studies in Sociology of Education, Vol. 26, no 1: 82-97 (2017, with Gerasimos Koustourakis and Dimitris Vergidis) and "A Foucauldian disciplinary theorization of inmate education in the Second Chance Schools in Greek prisons: A case study", Studies in the Education of Adults, Vol. 52, no 1: 101-118 (2020, with Gerasimos Koustourakis and Nikolaos Nikolakakos). E-mail: asimaki@upatras.gr

Website: http://www.edu-sw.upatras.gr/faculty/asimaki/

Vasiliki-Eleni Selechopoulou is PhD Student at the University of Nottingham, School of Education, Nottingham, U.K. She holds an M.Ed. in Educational Sciences and her scientific interests lie in the field of Sociology of Education, mainly focusing on teachers' education and their formation as teacher-subjects. Her empirical studies have been published in the proceedings of international and panhellenic conferences.

E-mail: vasiliki.selechopoulou@nottingham.ac.uk

Gerasimos Koustourakis (PhD) is Professor at the University of Patras, Department of Educational Sciences and Early Childhood Education, Greece. He is also a tutor in the postgraduate studies programme, Master in Education, in the Faculty of Humanities of Hellenic Open University teaching open and distance learning.

E-mail: koustourakis@upatras.gr Website: http://www.ecedu.upatras.gr/koustourakis

\section{References}

Abrahams, F. (2009). Examining the Preservice Practicum experience of undergraduate music education majors: exploring connections and dispositions through multiple perspectives. A critical grounded theory. Journal of Music Teacher Education, 19(1), 80-92. Available at: https://doi.org/10.1177/1057083709344044.

Aravanis, G. (1996). Discipline and Education: The role of punishment and rewards in primary school and kindergarten: theoretical approach-empirical research. Athens: Grigoris. 
Armstrong, P. (2015). The discourse of Michel Foucault: A Sociological Encounter. Critical Perspectives on Accounting, 27, 29-42. Available at: https://doi.org/10.1016/j.cpa.2013.10.009.

Asimaki, A., Koustourakis, G., \& Nikolakakos N. (2020). A Foucauldian disciplinary theorisation of inmate education in the Second Chance Schools in Greek prison: A case study. Studies in the Education of Adults, 52(1), 101-118. Available at: https://doi.org/10.1080/02660830.2019.1595341.

Asimaki, A., Nikolakakos N., \& Vergidis, D. (2016). The concepts of power and discipline in the theory of Michel Foucault. Scientific Yearbook Arethas, 5, 93-118.

Babbie, E. (2010). The Practice of Social Research (12th ed.). USA: Wadsworth.

Beck, C., \& Kosnik, C. (2002). Components of a Good Practicum Placement: Student Teacher Perceptions. Teacher Education Quarterly, 29(2), 81-98. Available at: http://teqjournal.org/Back\%20Issues/Volume\%2029/VOL29\%20PDFS/29 2/sp02b eck kosnick-29 2.pdf.

Braun, A. (2011). 'Walking yourself around as a teacher': gender and embodiment in student teachers' working lives. British Journal of Sociology of Education, 32(2), 275291. Available at: https://doi.org/10.1080/01425692.2011.547311.

Britzman, D. P. (2003). Practice makes practice: A critical study of learning to teach. New York: SUNY Press.

Buckland, R. (2016). The decision by approved mental health professionals to use compulsory powers under the mental health act 1983: A Foucauldian Discourse Analysis. British Journal of Social Work, 46, 46-62. Available at: https://doi.org/10.1093/bjsw/bcu114.

Butler, J. (2017). What is Critique? An essay on Foucault's Virtue. Athens: Plethron.

Deleuze, G. (2005). Foucault. Athens: Plethron.

Edwards, A., \& Collison, J. (1995). What Do Teacher Mentors Tell Student Teachers About Pupil Learning in Infant Schools?. Teachers and Teaching: theory and practice, 1(2), 265-279. Available at: https://doi.org/10.1080/1354060950010208.

Foucault, M. (1989). Discipline and Punish: The birth of the Prison. Athens: Kedros.

Foucault, M. (1990). The order of discourse. Athens: Iridanos.

Foucault, M. (1991). The microphysics of power. Athens: Ypsilon.

Foucault, M. (1994). Two lectures. In: K. Michael (Ed.), Critique and Power: Recasting the Foucault/Habermas debate (pp. 17-46). Cambridge: MIT Press.

Foucault, M. (2005). The history of sexuality: The will to knowledge (vol.1). Athens: Kedros.

Foucault, M. (2008). The Eye of Power. Thessaloniki: Vanias.

Foucault, M. (2010). Abnormal: Lectures at the College de France, 1974-1975. Athens: Estia.

Foucault, M. (2016a). The Punitive Society: Lectures at the Collège de France, 1972-1973. Athens: Plethron.

Foucault, M. (2016b). What is Critique?. Athens: Plethron.

Germanos, D. (1993). Space and educational processes: The pedagogical quality of space. Athens: Gutenberg.

Grawitz, M. (2006). Methodology in the Social Sciences (vol.2). Athens: Odisseas. 
Hildenbrand, S., \& Arndt, K. (2016). Student teachers' management practices in elementary classrooms: a qualitative study. Teacher Development, 20 (2), 147-161. Available at: https://doi.org/10.1080/13664530.2016.1143869.

Izadinia, M. (2016). Student teachers' and mentor teachers' perceptions and expectations of a mentoring relationship: do they match or clash? Professional Development in Education, 42(3), 387-402. Available at: https://doi.org/10.1080/19415257.2014.994136.

Jones, D., \& Ball, S. (1994). Michel Foucault and the Discourse of Education. In: I. Solomon, \& I. Kouzelis (Eds.), Discipline and Knowledge (pp. 169-178). Athens: E.M.E.A.

Karras, K. (2011). The teacher in a changing world. Athens: Gutenberg.

Kossivaki, F. (2003). The role of the teacher in post-modern school: Expectations, Perspectives, Limits. Athens: Gutenberg.

Koustourakis, G. (2007). The new educational policy for the reform of the curriculum and the change of school knowledge in the case of Greek compulsory education. International Studies in Sociology of Education, 17(1/2), 131-146. Available at: https://doi.org/10.1080/09620210701433878.

Koustourakis, G. (2018). Analysing the curriculum for students with mild and moderate learning difficulties concerning the teaching of pre-vocational skills. British Journal of Sociology of Education, 39(8), 1210-1225. Available at: https://doi.org/10.1080/01425692.2018.1497948.

Koutselini-Ioannidou, M. (1996). Discipline in primary school in a post-modern era. Modern Education, 90-91, 55-60.

Krippendorff, K. (2004). Content Analysis: Introduction to its Methodology (2nd ed). London: Sage.

Kyriazi, N. (2000). Sociological Research: Critical overview of methods and techniques. Athens: Ellinika Grammata.

Lazaroiu, G. (2013). Besley on Foucault's Discourse of Education. Educational Philosophy and Theory, 45(8), 821-832. Available at: https://doi.org/10.1080/00131857.2013.785092.

Lilha, M, \& Vinthagen S. (2014). Sovereign power, disciplinary power and biopower: resisting what power with what resistance? Journal of Political Power, 7(1), 107-126. Available at: https://doi.org/10.1080/2158379X.2014.889403.

Loizou, E. (2011). The diverse facets of power in early childhood mentor-student-teacher relationships. European Journal of Teacher Education, 34(4), 373-386. Available at: https://doi.org/10.1080/02619768.2011.587112.

Mason, J. (2002). Qualitative Researching (2nd ed.). London: Sage Publications.

McNay, M. (2004). Power and Authority in Teacher Education. The Educational Forum, 68(1), 72-81. Available at: https://doi.org/10.1080/00131720308984605.

Mialaret, G. (2012). Introduction. In: K. G. Karras, \& C. C. Wolhuter (Eds.), Teachers' education in the 21st century: Modern trends and challenges in teachers' education systems in 90 countries (pp. 21-23). Athens: Ion. 
Molla, T. \& Nolan, A. (2020). Teacher agency and professional practice. Teachers and Teaching, 26(1), 67-87. Available at: https://doi.org/10.1080/13540602.2020.1740196. Oikonomidis, V. (2007). Students judge their practicum: A case study. In: H. Hatzidimou, G. Konstantinos, P. Stravakou, \& K. Hatzidimou (Eds.). $5^{\text {th }}$ Panhellenic Conference of Greek Pedagogy and Educational Research (pp. 205-214). Thessaloniki: Aderfi Kyriakidi.

Pitsoe V., \& Letseka, M. (2013). Foucault's Discourse and Power: Implications for Instructionist Classroom Management. Open Journal of Philosophy, 3(1), 23-28. Available at: https://www.scirp.org/html/27781.html.

Rajuan, M., Beijaard D., \& Verloop, N. (2007). The role of the cooperating teacher: bridging the gap between the expectations of cooperating teachers and student teachers. Mentoring \& Tutoring: Partnership in Learning, 15(3), 223-242. Available at: https://doi.org/10.1080/13611260701201703.

Santoro, N. (1999). Relationships of power: An analysis of school practicum discourse. Journal of Intercultural Studies, 20(1), 31-42. Available at: https://doi.org/10.1080/07256868.1999.9963469

Silverman, D., \& Marvasti, A. (2008). Doing Qualitative Research: A Comprehensive Guide. London: Sage.

Solomon, I. (1992). Power and order in Modern Greek school: A typology of school spaces and practices 1820-1900. Athens: Alexandria.

Sumara, D. J., \& Luce-Kapler, R. (1996). (Un)becoming a teacher: Negotiating identities while learning to teach. Canadian Journal of Education, 21(1), 65-83.

Tasi, S. (2014). The 'disciplinary society' of Michel Foucault and the autopoieticly developing society of Niklas Luhmann. Review of Social Research, 142, 101- 121.

Troulinou, L. (1991). Power and Law in Foucault. In: M. Foucault, The microphysics of power (pp. 170-182). Athens: Ypsilon.

Vamvoukas, M. (2000). Introduction to psycho-pedagogical research and methodology. Athens: Grigoris.

Veyne, P. (2011). Foucault: His thought, his character. Athens: Estia.

Wexler, L. J. (2020). "Empowering" Instead of "Crushing an Idea": One Student Teacher/Mentor Teacher Pair's Story of Learning and Growing. The New Educator, 16(3), 265-278. Available at: https://doi.org/10.1080/1547688X.2020.1727594.

White, M. D., \& Marsh, E. E. (2006). Content Analysis: A Flexible Methodology. Library Trends, 55(1), 22-45. Available at: https://muse.jhu.edu/article/202361. 

to copy, distribute, transmit or adapt the article content, providing a proper, prominent and unambiguous attribution to the authors in a manner that makes clear that the materials are being reused under permission of a Creative Commons License. Views, opinions and conclusions expressed in this research article are views, opinions and conclusions of the author(s). Open Access Publishing Group and European Journal of Education Studies shall not be responsible or answerable for any loss, damage or liability caused in relation to/arising out of conflicts of interest, copyright violations and inappropriate or inaccurate use of any kind content related or integrated into the research work. All the published works are meeting the Open Access Publishing requirements and can be freely accessed, shared, modified, distributed and used in educational, commercial and non-commercial purposes under a Creative Commons Attribution 4.0 International License (CC BY 4.0). 